\title{
Establishment and associated factors of health records among young Chinese migrants
}

Hong Shi ${ }^{1}$, Xiumin Zhang ${ }^{1 *}$ D, Xiangrong $\mathrm{Li}^{1}$, Zheng Ren ${ }^{1}$, Hanfang Zhao ${ }^{1}$, Minfu He ${ }^{1}$, Xinwen Fan ${ }^{1}$, Xia Guo ${ }^{1}$, Shuang Zha', Shuyin Qiao', Yuyu Li ${ }^{1}$, Yajiao Pu and Hongjian Liu ${ }^{1}$

\begin{abstract}
Background: Most Chinese migrants have been faced with obstacles to getting access to local public health services. Young migrants among internal migrants make a major contribution to the economy. However, the establishment of their health records has been ignored. This research was aimed at exploring the status and associated factors of the establishment of health records among young Chinese migrants.
\end{abstract}

Methods: Data were obtained from the 2017 China Migrants Dynamic Survey (CMDS). Chi-square test and binary logistic regression were performed to investigate the associated factors of the establishment of health records among young Chinese migrants.

Results: Approximately $30.2 \%$ of young migrants had their health records established in inflow communities. Urban residence, medical insurance (insured), and lower average monthly household income were attributed to the establishment of more health records. Young migrants who were in northeast China and across provinces and immigrated for working or engaging in trade were less likely to have health records established. Young migrants who participated in social activities and public affairs activities and took type of people in touch as natives in the inflow area showed a higher possibility of establishing health records. Meanwhile, receiving health education and hearing about national basic public health services (BPHSs) were beneficial for establishing the health records of more young migrants.

Conclusion: This study showed that the health records of young migrants had a relatively low establishment rate. Sociodemographic and migration characteristics, health status, public health services, and social integration factors were all related to the health record establishment of young Chinese migrants.

Keywords: Young migrants, Health records, Associated factors

\footnotetext{
*Correspondence: xiu_min@jlu.edu.cn; zhangxiumin63@163.com

'Department of Social Medicine and Health Management, School of Public Health, Jilin University, Changchun 130021, China

Full list of author information is available at the end of the article
}

(c) The Author(s). 2021 Open Access This article is licensed under a Creative Commons Attribution 4.0 International License, which permits use, sharing, adaptation, distribution and reproduction in any medium or format, as long as you give appropriate credit to the original author(s) and the source, provide a link to the Creative Commons licence, and indicate if changes were made. The images or other third party material in this article are included in the article's Creative Commons licence, unless indicated otherwise in a credit line to the material. If material is not included in the article's Creative Commons licence and your intended use is not permitted by statutory regulation or exceeds the permitted use, you will need to obtain permission directly from the copyright holder. To view a copy of this licence, visit http://creativecommons.org/licenses/by/4.0/. The Creative Commons Public Domain Dedication waiver (http://creativecommons.org/publicdomain/zero/1.0/) applies to the data made available in this article, unless otherwise stated in a credit line to the data. 


\section{Background}

Changes have taken place in urban and rural population structures due to the current construction of new urbanization. Migration is the core issue of the recent urbanization process of China [1]. The 2018 Report on China's Migrant Population Development revealed that the number of migrants in China reached up to 244 million in 2017 [2]. Young migrants among internal migrants make a major contribution to the economy and have a direct or indirect impact on the development of politics, economy, culture, and other aspects in China [3]. Concurrently, research has shown that younger migrants are most likely to experience a decline in health after migration [4]. Furthermore, they are much less likely to be aware of their conditions, suffer from unnoticed high health risks leading to their vulnerability to long-term health problems [5], and find it impossible to seek medical attention by themselves [6]. A worrying finding is that migration characteristics and inattention to health result in the vulnerability of young migrants to ill health. Given a large number of Chinese migrants, it is urgent to address the health problems brought by migration, which poses particular demands on the basic public health service system.

"Equalization of Essential Public Health Services" is a rare national program that covers the prevention and control of non-communicable diseases (NCDs) for internal migrants [7]. The latest basic public health services (BPHS) package includes 14 categories which involve establishing original items like health records and health education, adding health supervision assistance, and promoting free contraceptives and health literacy [8]. As the main item of the equalization of BPHSs, health records include basic personal information, health examination information, health management of key populations and other medical and health service records. Specifically, basic personal information includes name, gender, education level, marital status, basic health information, etc. Health examination information includes general health examination, lifestyle, health status, etc. Health management of key populations mainly refers to the health management records of children aged 0-6, pregnant women, the elderly and individuals with chronic diseases, etc. Other medical and health service records include the records of receive and transfer. The establishment of health records is funded by the state and provided to residents free of charge. The residents' health records are coded uniformly, and managed by community health centers. Health records are the basis for implementing other health services, play a significant role in providing sufficient access to public health services, work as management tools assisting medical staff in storing, accessing and managing the personal health information of residents so as to make decisions on their health status [9], effectively control health risk factors and enable patients and health providers to make right decisions on health management or treatment [10].

In response to the right and health protection of migrants, "Healthy China 2030" explicitly proposes to promote the equalization of BPHSs to gradually narrow the differences in basic health services and the inequality of health between populations [11]. "13th Five-Year Plan for Health and Wellness" has made clear demands to facilitate the better management of migrants and promote the equity of BPHSs [12]. Despite the great emphasis placed in the national policy on the equity between migrants and residents, most migrants are excluded from local public health services in the cities where they live. Existing literature has indicated that people who have been working or living outside for a long time encounter barriers when getting access to BPHSs due to their weak health awareness and failure to establish health records [13]. That is to say, migrants cannot enjoy basic health services like local residents because of migration status.

As highlighted above, it is of importance to promote the above-mentioned national program and establish the health records of more young migrants. However, data about the situation of young migrants are minimal because most of the research has focused on the migrants who are ordinary and elderly and suffer from chronic diseases $[9,14,15]$. Moreover, a number of previous studies emphasized the socio-economic and demographic characteristics affecting health records establishment $[16,17]$. Considering the potential impact of more comprehensive migration characteristics and social integration factors, this analysis was aimed at exploring the status and associated factors of the establishment of health records among young Chinese migrants by using national survey data in 2017, which can help to identify the barriers to the health record establishment of young migrants and play a crucial role in providing robust evidence and recommendations for targeted interventions to establish more health records.

\section{Methods}

\section{Data source and research sample}

Data were retrieved from the 2017 China Migrants Dynamic Survey (CMDS), a cross-sectional and nationally representative survey organized by the National Health Commission of the People's Republic of China [18]. A total of 169,989 subjects were recruited, who were at the age of 15 and above, lacked a local Hukou (rural or urban residence) and had dwelled in their current location for no less than 1 month.

The subjects of this study are young migrants. The World Health Organization limits the age of young people to 44 [19]. Young migrants in this study refer to 
the migrants aged between 15 and 44 . With regard to the idea of this study, the management and service specification of residents' health records states that subjects are those who have lived in their current residence for over 6 months with a local Hukou. Young migrants who had settled in their current residence for less than half a year were excluded. As a result, a final sample of 115, 730 was obtained.

\section{Variables}

\section{Dependent variables}

The establishment status of the health records of young migrants was measured by the survey question "Have you established your health records in your community?" The establishment of health records was coded as "yes $=1$ " if the reply was "Yes, established", and "no=0" if the answer was "No, I've never heard of it", "No, but I've heard it" or "I don't know about it" [20, 21].

\section{Independent variables}

Sociodemographic characteristics included gender (male or female), age (15-29 or 30-44), ethnicity (Han or minority), marital status (single (unmarried, widowed or divorced), or married (first or non-first marriage)), Hukou status, education level (primary school or below or middle/high school/college degree or above), medical insurance (uninsured/insured), and average monthly household income (below 3000/3001-5000/above 5001 yuan).

Migration characteristics were measured through five migrant-related variables, namely sample area (east/central/west/northeast), extent (inter-provincial/intra-provincial/inter-country within the city) and duration of migration ( $\leq 1$ year $/ 2-4$ years $/ 5-9$ years $/ \geq 10$ years), reasons for migration (working or engaging in trade/following the migration of family members/marriage-related/ else) as well as settlement willingness (no/yes).

Health status and public health services factors included self-rated health (good/neutral/poor), hypertension or type 2 diabetes (no/yes), distance of medical facilities $(\leq 15 \mathrm{~min} />15 \mathrm{~min}$ ), hearing about national BPHSs (no/yes) and health education (no/yes). The status of health education was measured by the survey question "Did you receive health education in your community last year?" whose answers have the following nine items: Occupational disease prevention, sexually transmitted disease (STD)/acquired immune deficiency syndrome (AIDS) prevention, reproductive health and contraception, tuberculosis prevention, smoking control, mental health, chronic disease prevention, maternal and child health care as well as self-help in public emergencies. Health education was coded as "no $=0$ " if none of the above items were selected and otherwise "yes $=1 . "$
According to existing studies and available data [2224], four variables were constructed to measure the social integration of migrants, including the participation in social activities and public affairs activities, willingness to integrate and type of people in touch. Four questions that were selected to measure the social integration of migrants are as follows. (1) "Have you ever participated in the activities of the following organizations in the inflow area?" whose answers have the following six items: Union, Volunteer's Association, Alumni Association, Townsmen Association, Hometown Chamber of Commerce, and others. Participation in social activities was coded as "no $=0$ " if none of the above activities were attended and otherwise "yes=1." (2) "Have you ever had any of the following behaviors?" whose answers have the following five items: advise or supervise community or village management, provide government departments with policy recommendations, and participate in discussions on state affairs or social events online, donation, blood donation, and volunteer activities as well as party branch and league activities. The participation in public affairs activities was coded as "no $=0$ " if none of the above behaviors appeared and otherwise "yes=1." (3) "Do you agree that you are willing to be a part of local residents." The willingness to integrate was coded as "no $=0$ " if the response was "totally disagree" or "disagree" and "yes $=1$ " if the response was "agree" or "totally agree." (4) Type of people in touch was measured by the survey question "In your spare time, who do you associate with most in the inflow area," and coded as "people from the same hometown=1," "natives in the inflow area=2," immigrants from places other than hometown $=3$," and "little contact with others $=4 . "$

\section{Statistical analysis}

Statistical analyses were carried out by using Statistical Product and Service Solutions (SPSS) 24.0 (IBM Corp, Armonk, NY, USA). Demographic information and the establishment status of health records were described using descriptive statistical analysis. The difference in the health record establishment of young migrants with various characteristics was analyzed by performing a chisquare test. Multivariate analysis was tested by binary logistic regression. The associated factors of the establishment of health records among young migrants in China were further investigated by performing binary logistic regression and using the odd ratio (OR) and 95\% confidence intervals (CIs). A two-side $p$ value less than 0.05 was considered as statistically significant. Before conducting binary logistic regression, independent variables were tested for co-linearity according to tolerance values and the VIF (variance inflation factor). The criteria values for tolerance and VIF ( $\leq 0.10$ and $\geq 10$, respectively) to identify co-linearity [25]. 
Since the establishment of health records is classified as either "yes" or "no," a binary logistic model was used to fit the data and explore the associated factors of the establishment of health records among young Chinese migrants. The formula of binary logistic regression is as follows:

$$
\operatorname{Logit}(p)=\ln \left[\frac{p}{1-p}\right]=\alpha+\beta_{1} X_{1}+\beta_{2} X_{2}+\cdots+\beta_{m} X_{m}
$$

where $p$ denotes the probability of establishing health records, $\alpha$ is a constant term, and the fitting regression coefficients are expressed as $\beta_{j}(j=1,2, \ldots, m)$, the potential explanatory variables are expressed as $X_{j}(j=1,2, \ldots, m)$. The OR indicator is able to be directly calculated in logistic regression by $O R=e^{\beta}$.

\section{Results}

\section{Characteristics of young migrants}

$50.8 \%$ were females among 115,730 young migrants who were aged 32.00 on average, with a standard deviation of 6.50. Most participants were rural (82.8\%) and married (79.8\%) with a middle school diploma (43.3\%). Most young migrants bought medical insurance (91.7\%), among whom about $58.2 \%$ had an average monthly household income of above 5001 yuan. As for migration characteristics, more young internal migrants (41.7\%) were in eastern regions, and most of the participants were inter-provincial young migrants $(47.8 \%)$, with the duration of migration $2-4$ years $(33.3 \%)$. The sample population of this study immigrated for working or engaging in trade (84.2\%), with settlement willingness (84.2\%). With regard to health status and PHS characteristics, the majority of young migrants had good self-rated health $(87.0 \%)$, about $2.0 \%$ had hypertension or type 2 diabetes, the distance of medical facilities was $\leq 15$ min (84.2\%), 61.8\% had heard about national BPHSs, and most received health education $(75.1 \%)$. Regarding social integration, $49.0 \%$ of young migrants participated in social activities, $45.2 \%$ participated in public affairs activities, $93.7 \%$ were willing to integrate and type of people in touch was natives in the inflow area $(34.5 \%)$.

\section{Establishment status of health records}

The results indicated that about $30.2 \%$ of young migrants established their health records in their local communities. Establishment rate of health records among young migrants in the east, central, west, and northeast areas were $26.0 \%, 41.3 \%, 30.9 \%$, and $24.7 \%$, respectively.
Factors associated with the establishment status of health records

Univariate analysis indicated that gender, age, marital status, Hukou status, education level, medical insurance, and average monthly household income were significantly associated with health record establishment (Table 1).

Univariate analysis indicated that sample area, extent, and duration of migration, reasons for migration and settlement willingness were significantly related to health record establishment (Table 2).

Univariate analysis indicated that self-rated health, distance of medical facilities, health education, and hearing about national BPHSs were significantly associated with health record establishment (Table 3).

Univariate analysis indicated that participation in social activities and public affairs activities, willingness to integrate and type of people in touch were significantly related to health record establishment (Table 4).

A co-linearity analysis showed a VIF $<10$ and no colinearity among the independent variables (Table 5). Table 6 presents the binary logistic regression results of factors that were related to the establishment of health records among young migrants and also identified as variables in the multivariate analysis if observed to be correlated with the health record establishment of young migrants in univariate analysis. The binary logistic regression indicated that young migrants were more inclined to have established their health records if female; married and insured; and having urban residence; a primary school diploma or below; and an average monthly household income of less than 3000 yuan. Those who were northeast and inter-province young migrants, had duration of migration $\leq 1$ year and immigrated for working or engaging in trade without settlement willingness were less likely to have established health records. Good self-rated health, distance of medical facilities $\leq 15 \mathrm{~min}$, health education and hearing about national BPHSs were positive factors. Meanwhile, young migrants who participated in social activities and public affairs activities and took type of people in touch as natives in the inflow area had a higher likelihood of having established health records.

\section{Discussion}

The designated policy pointed out that health records should keep an establishment rate of above 75\% [15]. Previous studies have shown that the health records of residents in urban and rural areas had an establishment rate of $80.6 \%$ [13], satisfying the policy requirement. However, this study found that $30.2 \%$ of young migrants had established health records in their local communities, which fell below the national recommendation. Furthermore, the health record establishment rate of young 
Table 1 Sociodemographic characteristics and the establishment of health records $(N=115,730)$

\begin{tabular}{|c|c|c|c|c|c|}
\hline \multirow[t]{2}{*}{ Variables } & \multirow{2}{*}{$\begin{array}{l}\text { Total } \\
N(\%)\end{array}$} & \multicolumn{2}{|c|}{ Establishment of health records } & \multirow[t]{2}{*}{$x^{2}$} & \multirow[t]{2}{*}{$p$} \\
\hline & & Yes & No & & \\
\hline Gender & & & & 97.523 & $<0.001$ \\
\hline Male & $56,921(49.2)$ & $16,429(28.9)$ & $40,492(71.1)$ & & \\
\hline Female & $58,809(50.8)$ & $18,542(31.5)$ & $40,267(68.5)$ & & \\
\hline Age & & & & 18.004 & $<0.001$ \\
\hline $15-29$ & $44,206(38.2)$ & $13,036(29.5)$ & $31,170(70.5)$ & & \\
\hline $30-44$ & $71,524(61.8)$ & $21,935(30.7)$ & $49,589(69.3)$ & & \\
\hline Ethnicity & & & & 1.477 & 0.224 \\
\hline Han & $104,512(90.3)$ & $31,525(30.2)$ & $72,987(69.8)$ & & \\
\hline Minority & $11,218(9.7)$ & $3446(30.7)$ & $7772(69.3)$ & & \\
\hline Marital status & & & & 251.598 & $<0.001$ \\
\hline Married & $92,385(79.8)$ & $28,911(31.3)$ & $63,474(68.7)$ & & \\
\hline Single & $23,345(20.2)$ & $6060(26.0)$ & $17,285(74.0)$ & & \\
\hline Hukou status & & & & 60.538 & $<0.001$ \\
\hline Rural & $95,801(82.8)$ & $28,490(29.7)$ & $67,311(70.3)$ & & \\
\hline Urban & $19,929(17.2)$ & $6481(32.5)$ & $13,448(67.5)$ & & \\
\hline Education level & & & & 150.702 & $<0.001$ \\
\hline Primary school or below & $12,066(10.4)$ & $3265(27.1)$ & $8801(72.9)$ & & \\
\hline Middle school & $50,100(43.3)$ & $14,658(29.3)$ & $35,442(70.7)$ & & \\
\hline High school & $27,998(24.2)$ & $8782(31.4)$ & $19,216(68.6)$ & & \\
\hline College degree or above & $25,566(22.1)$ & $8266(32.3)$ & $17,300(67.7)$ & & \\
\hline Medical insurance & & & & 319.981 & $<0.001$ \\
\hline Insured & $10,6078(91.7)$ & $32,827(30.9)$ & $73,251(69.1)$ & & \\
\hline Uninsured & $9652(8.3)$ & $2144(22.2)$ & $7508(77.8)$ & & \\
\hline Average monthly household income & & & & 11.666 & 0.003 \\
\hline$\leq 3000$ & $14,325(12.4)$ & $4173(29.1)$ & $10,152(70.9)$ & & \\
\hline $3001-5000$ & $34,054(29.4)$ & $10,452(30.7)$ & $23,602(69.3)$ & & \\
\hline$\geq 5001$ & $67,351(58.2)$ & $20,346(30.2)$ & $47,005(69.8)$ & & \\
\hline
\end{tabular}

migrants was relatively lower than that of the general population. Undeniably, Chinese migrants and residents show inequalities in the utilization of BPHSs. Considering the importance of health status and the low establishment rate of health records among young migrants, it is necessary to make targeted interventions to help to establish more health records based on associated factors.

In line with previous research, young migrants with a non-agricultural Hukou had a high possibility of establishing health records, which may be because migrants with an agricultural Hukou are more marginalized in many ways [9]. Basic medical insurance is the major source of healthcare financing in China, including the Urban Employee Basic Medical Insurance, the New Rural Cooperative Medical Scheme, and the Urban Residents Basic Medical Insurance. The insurance policies, including the insurance premium and reimbursement coverage, are different to the various target populations [26]. The household registration system directly affected the participation and use of medical insurance [27]. Young migrants who were insured were found to have a higher possibility of establishing health records, which was consistent with prior studies [14]. Young migrants with medical insurance may tend to be more aware of their own health initiatively. Therefore, policy-makers should pay more attention to the living conditions and improvement of utilization level of public health services of young migrants in agricultural Hukou. It was observed that middle school or above education and higher household income had negative impact on the health record establishment of young migrants. This result is contrary to the result of univariate analysis. The possible reason is that education level and average monthly household income may be confounded by other factors in univariate analysis. For the high levels of employment 
Table 2 Migration characteristics and the establishment of health records $(N=115,730)$

\begin{tabular}{|c|c|c|c|c|c|}
\hline \multirow[t]{2}{*}{ Variables } & \multirow{2}{*}{$\begin{array}{l}\text { Total } \\
N(\%)\end{array}$} & \multicolumn{2}{|c|}{ Establishment of health records } & \multirow[t]{2}{*}{$x^{2}$} & \multirow[t]{2}{*}{$p$} \\
\hline & & Yes & No & & \\
\hline Sample area & & & & 1699.815 & $<0.001$ \\
\hline East & $48,289(41.7)$ & $12,548(26.0)$ & $35,741(74.0)$ & & \\
\hline Central & $20,210(17.5)$ & $8337(41.3)$ & $11,873(58.7)$ & & \\
\hline West & $39,221(33.9)$ & $12,106(30.9)$ & $27,115(69.1)$ & & \\
\hline Northeast & $8010(6.9)$ & $1980(24.7)$ & $6030(75.3)$ & & \\
\hline Extent of migration & & & & 1012.122 & $<0.001$ \\
\hline Inter-provincial & $55,282(47.8)$ & $14,225(25.7)$ & $41,057(74.3)$ & & \\
\hline Intra-provincial & $39,377(34.0)$ & $13,438(34.1)$ & $25,939(65.9)$ & & \\
\hline Inter-country within the city & $21,071(18.2)$ & $7308(34.7)$ & $13,763(65.3)$ & & \\
\hline Duration of migration & & & & 93.896 & $<0.001$ \\
\hline$\leq 1$ & $18,536(16.0)$ & $5196(28.0)$ & $13,340(72.0)$ & & \\
\hline $2-4$ & $38,532(33.3)$ & $11,925(30.9)$ & $26,607(69.1)$ & & \\
\hline $5-9$ & $34,861(30.1)$ & $10,957(31.4)$ & $23,904(68.6)$ & & \\
\hline$\geq 10$ & $23,801(20.6)$ & $6893(29.0)$ & $16,908(71.0)$ & & \\
\hline Reasons of migration & & & & 207.260 & $<0.001$ \\
\hline Working or engaging in trade & $97,395(84.2)$ & $28,652(29.4)$ & $68,743(70.6)$ & & \\
\hline Following the migration of family members & $10,415(9.0)$ & $3526(33.9)$ & $6889(66.1)$ & & \\
\hline Marriage-related & $3660(3.2)$ & $1374(37.5)$ & $2286(62.5)$ & & \\
\hline Else & $4260(3.7)$ & 1419 (33.3) & $2841(66.7)$ & & \\
\hline Settlement willingness & & & & 330.920 & $<0.001$ \\
\hline Yes & $97,473(84.2)$ & $30,490(31.3)$ & $66,983(68.7)$ & & \\
\hline No & $18,257(15.8)$ & $4481(24.5)$ & $13,776(75.5)$ & & \\
\hline
\end{tabular}

benefits and medical benefits, those migrants who with higher education level would be less likely to go to community health center. Moreover, they might have more stressful work, and thus have less time to make use of public health services including the establishment of health records. Young migrants whose household income was higher would be more likely to visit doctors in hospitals rather than community health centers. They would be more likely to use high-quality health services, which would possibly lead to their neglect of health records [28]. In recent years, the Chinese government has taken several measures to promote equal access to basic public health services among residents and migrants. Therefore, the migrants with low socioeconomic status had positive impact on the health record establishment, which reflects the goal of equalization of basic public health services.

Migration characteristics substantially contributed to the health inequality among young migrants who tend to be vulnerable to poor health conditions and utilize insufficient BPHSs due to external environmental factors and internal cultural shock in the cities where they live. It was noticed that northeast and inter-province migrant status, duration of migration $\leq 1$ year, working or engaging in the trade as the reason for migration and no settlement willingness had a negative impact on the health record establishment of young migrants, which was parallel with previous studies [14, 29]. It is likely that environments and conditions in different areas were diverse. Migrants were faced with challenges navigating a new and unfamiliar health system [30]. Young internal migrants in northeastern regions showed a lower establishment rate of health records than those in central and western China, which was attributed to the economic level and distribution of health resources among different regions. Meanwhile, it is possible that young migrants owning short-term residence and immigrating for working or engaging in trade had less personal time and health care awareness to comprehend local specific health and preventive information, and little motivation to establish health records. Based on the above findings, it is essential to optimize the allocation of corresponding health elements in northeastern regions to narrow regional gaps, and goal-oriented policies and ensuring mechanisms should be made to enhance fairness of financing so as to promote accessibility and equality. Community health centers should strengthen propaganda and guidance to heighten the understanding of 
Table 3 Health status and public health services factors and the establishment of health records $(N=115,730)$

\begin{tabular}{|c|c|c|c|c|c|}
\hline \multirow[t]{2}{*}{ Variables } & \multirow{2}{*}{$\begin{array}{l}\text { Total } \\
N(\%)\end{array}$} & \multicolumn{2}{|c|}{ Establishment of health records } & \multirow[t]{2}{*}{$x^{2}$} & \multirow[t]{2}{*}{$p$} \\
\hline & & Yes & No & & \\
\hline Self-rated health & & & & 114.668 & $<0.001$ \\
\hline Good & $100,693(87.0)$ & $30,985(30.8)$ & $69,708(69.2)$ & & \\
\hline Neutral & $13,834(12.0)$ & $3688(26.7)$ & $10,146(73.3)$ & & \\
\hline Poor & $1203(1.0)$ & $298(24.8)$ & $905(75.2)$ & & \\
\hline Hypertension or type 2 diabetes & & & & 0.655 & 0.418 \\
\hline Yes & $2339(2.0)$ & $689(29.5)$ & $1650(70.5)$ & & \\
\hline No & $113,391(98.0)$ & $34,282(30.2)$ & $79,109(69.8)$ & & \\
\hline Distance of medical facilities & & & & 148.509 & $<0.001$ \\
\hline$\leq 15 \min$ & $97,403(84.2)$ & $30,128(30.9)$ & $67,275(69.1)$ & & \\
\hline$>15 \min$ & $18,327(15.8)$ & $4843(26.4)$ & $13,484(73.6)$ & & \\
\hline Health education & & & & $7,195.044$ & $<0.001$ \\
\hline Yes & $86,967(75.1)$ & $32,006(36.8)$ & $54,961(63.2)$ & & \\
\hline No & $28,763(24.9)$ & $2965(10.3)$ & $25,798(89.7)$ & & \\
\hline Hearing about national BPHSs & & & & $20,561.108$ & $<0.001$ \\
\hline Yes & $71,479(61.8)$ & $32,485(45.4)$ & $38,994(54.6)$ & & \\
\hline No & $44,251(38.2)$ & $2486(5.6)$ & 41,765 (94.4) & & \\
\hline
\end{tabular}

local health policies and establish the health records of more young migrants.

Young migrants who received health education and heard about national BPHSs showed a higher likelihood of establishing health records. These results indicated that health education and hearing about national BPHSs had positive impact on the health record establishment of young migrants. Apart from helping to improve the health conditions of young migrants indirectly by identifying their health risk factors, keeping healthy habits and shaping individual behavior, health education assists young migrants in gaining a better understanding of the advantages of establishing health records, removes privacy concerns and social distrust, and advances the health literacy and health consciousness of young migrants gradually. However, only less than $50 \%$ of migrants with health education or who know about national BPHSs established health records. These results suggested that providing health education or providing information on national BPHSs was not enough to establish health record in young

Table 4 Social integration characteristics and the establishment of health records $(N=115,730)$

\begin{tabular}{|c|c|c|c|c|c|}
\hline \multirow[t]{2}{*}{ Variables } & \multirow{2}{*}{$\begin{array}{l}\text { Total } \\
N(\%)\end{array}$} & \multicolumn{2}{|c|}{ Establishment of health records } & \multirow[t]{2}{*}{$x^{2}$} & \multirow[t]{2}{*}{$p$} \\
\hline & & Yes & No & & \\
\hline Participation in social activities & & & & 1859.835 & $<0.001$ \\
\hline Yes & $56,653(49.0)$ & $20,487(36.2)$ & $36,166(63.8)$ & & \\
\hline No & $59,077(51.0)$ & $14,484(24.5)$ & $44,593(75.5)$ & & \\
\hline Participation in public affairs activities & & & & 1405.301 & $<0.001$ \\
\hline Yes & $52,289(45.2)$ & $18,715(35.8)$ & $33,574(64.2)$ & & \\
\hline No & $63,441(54.8)$ & $16,256(25.6)$ & $47,185(74,4)$ & & \\
\hline Willingness to integrate & & & & 191.433 & $<0.001$ \\
\hline Yes & $108,495(93.7)$ & $33,308(30.7)$ & $75,187(69.3)$ & & \\
\hline No & $7235(6.3)$ & $1663(23.0)$ & $5572(77.0)$ & & \\
\hline Type of people in touch & & & & 547.330 & $<0.001$ \\
\hline People from the same hometown & $39,097(33.8)$ & $11,266(28.8)$ & $27,831(71.2)$ & & \\
\hline Natives in the inflow area & $39,975(34.5)$ & $13,774(34.5)$ & $26,201(65.5)$ & & \\
\hline Immigrants from places other than hometown & $13,621(11.8)$ & $3713(27.3)$ & $9908(72.7)$ & & \\
\hline Little contact with others & $23,037(19.9)$ & $6218(27.0)$ & $16,819(73.0)$ & & \\
\hline
\end{tabular}


Table 5 Co-linearity analysis of factors that associated with health records establishment of young Chinese migrants

\begin{tabular}{|c|c|c|c|c|c|}
\hline \multirow[t]{2}{*}{ Variables } & \multicolumn{2}{|c|}{ Collinear statistics } & \multirow[t]{2}{*}{ Variables } & \multicolumn{2}{|c|}{ Collinear statistics } \\
\hline & Tolerance & VIF & & Tolerance & VIF \\
\hline Gender & 0.928 & 1.078 & Reasons of migration & 0.928 & 1.077 \\
\hline Age & 0.731 & 1.368 & Settlement willingness & 0.946 & 1.057 \\
\hline Marital status & 0.730 & 1.370 & Self-rated health & 0.975 & 1.025 \\
\hline Hukou status & 0.837 & 1.195 & Distance of medical facilities & 0.989 & 1.011 \\
\hline Education level & 0.734 & 1.362 & Health education & 0.856 & 1.168 \\
\hline Medical insurance & 0.967 & 1.034 & Hearing about national BPHSs & 0.873 & 1.145 \\
\hline Average monthly household income & 0.819 & 1.221 & Participation in social activities & 0.828 & 1.208 \\
\hline Sample area & 0.878 & 1.140 & Participation in public affairs activities & 0.857 & 1.167 \\
\hline Extent of migration & 0.895 & 1.117 & Willingness to integrate & 0.968 & 1.033 \\
\hline Duration of migration & 0.894 & 1.118 & Type of people in touch & 0.961 & 1.041 \\
\hline
\end{tabular}

VIF Variance inflation factor

Chinese migrants. Therefore, it is essential to adopt effective methods to implement health education and promotion in the community $[18,31]$. Specifically, materials about BPHSs should be posted in the publicity column of the community, to popularize the ways and functions of establishing health records, meanwhile, electronic information-based health education channels including the Internet and new media should be developed to improve the quality of health education. Strengthening health literacy and adequate public health knowledge of young migrants aims to significantly promote the establishment of health records. Moreover, other factors should also be considered to increase the proportion of young Chinese migrants who establish health record.

Previous studies reported that community activities were conducive to improving the accessibility of health services among internal migrants [32]. The results of this study showed that young migrants participating in social activities and public affairs activities were more inclined to establish health records than those without. In addition, natives in the inflow area as type of people in touch made significant positive contributions to health record establishment. High-integrated young migrants were more familiar with community health centers and acceptable to the health information of current residence. Health information becomes an enabling factor that promotes the utilization of public health services. The reasons for migration were parallel with previous studies, suggesting that internal migrants who had better social integration were more inclined to utilize public health services [29]. Young migrants who had social interaction with natives in the inflow area could get more functional and emotional social support [33] to develop self-identity and a sense of social belonging. Meanwhile, natives in the inflow area can help them to be informed of local preventive measures, inevitably affecting the establishment of health records among young migrants in inflow communities. Therefore, the community should notice the importance of more social cohesion among young migrants [34]. A variety of community activities should be organized to create an enthusiastic environment. More interventions should be implemented to encourage positive social adaptation and interaction between natives in the inflow area and young migrants.

\section{Limitations}

The limitations of this study should be considered. First, cross-sectional data were used, preventing the interpretation of causal relationships. Second, subjective biases cannot be ruled out because of self-reported information on the establishment of health records and status. Thirdly, some variables considered in our study cannot be modified. There are no effective interventions to establish health records based on these variables. More modifiable factors should be further studied in future. Finally, the factors which were associated with the adoption of health records should be identified from the perspectives of health service providers and users. This study was based on the associated factors of health service users. More essential potential factors of health service providers should be further studied and confirmed in follow-up studies.

\section{Conclusion}

This study showed that the health records of young migrants had a relatively low establishment rate. Sociodemographic and migration characteristics, health status, public health services, and social integration factors were all associated with health record establishment. Due to heterogeneity, policies and interventions should take into account different subgroups, especially vulnerable ones, strengthen the impact of health education on the popularization of health knowledge and the establishment of health records, and improve the health level of young migrants. The multifaceted association suggested that 
Table 6 Binary logistic regression analysis of factors associated with health records establishment of young Chinese migrants $(\mathrm{N}=$ 115,730)

\begin{tabular}{|c|c|c|c|c|c|}
\hline \multirow[t]{2}{*}{ Variables } & \multirow[t]{2}{*}{$B$} & \multirow[t]{2}{*}{$p$} & \multirow[t]{2}{*}{ OR } & \multicolumn{2}{|c|}{$95 \% \mathrm{Cl}$} \\
\hline & & & & Lower & Upper \\
\hline Gender (Ref = male) & 0.049 & 0.001 & 1.050 & 1.019 & 1.082 \\
\hline Marital status (Ref = single) & 0.194 & $<0.001$ & 1.214 & 1.166 & 1.263 \\
\hline Hukou status (Ref = rural) & 0.086 & $<0.001$ & 1.090 & 1.046 & 1.135 \\
\hline \multicolumn{6}{|l|}{ Education level (Ref = primary school or below) } \\
\hline Middle school & -0.095 & $<0.001$ & 0.910 & 0.863 & 0.958 \\
\hline High school & -0.156 & $<0.001$ & 0.856 & 0.809 & 0.906 \\
\hline College degree or above & -0.196 & $<0.001$ & 0.822 & 0.774 & 0.874 \\
\hline Medical insurance (Ref = uninsured) & 0.163 & $<0.001$ & 1.177 & 1.112 & 1.246 \\
\hline \multicolumn{6}{|l|}{ Average monthly household income ( Ref $=\leq 3000$ ) } \\
\hline $3001-5000$ & -0.036 & 0.153 & 0.964 & 0.918 & 1.014 \\
\hline$\geq 5001$ & -0.116 & $<0.001$ & 0.891 & 0.848 & 0.935 \\
\hline \multicolumn{6}{|l|}{ Sample area (Ref = northeast) } \\
\hline East & 0.046 & 0.160 & 1.047 & 0.982 & 1.116 \\
\hline Central & 0.477 & $<0.001$ & 1.611 & 1.507 & 1.722 \\
\hline West & 0.072 & 0.025 & 1.075 & 1.009 & 1.145 \\
\hline \multicolumn{6}{|l|}{ Extent of migration (Ref = inter-provincial) } \\
\hline Intra-provincial & 0.176 & $<0.001$ & 1.192 & 1.153 & 1.233 \\
\hline Inter-country within the city & 0.099 & $<0.001$ & 1.104 & 1.058 & 1.151 \\
\hline \multicolumn{6}{|l|}{ Duration of migration (Ref $=\leq 1$ ) } \\
\hline $2-4$ & 0.096 & $<0.001$ & 1.100 & 1.053 & 1.150 \\
\hline $5-9$ & 0.109 & $<0.001$ & 1.115 & 1.066 & 1.167 \\
\hline$\geq 10$ & 0.048 & 0.055 & 1.050 & 0.999 & 1.103 \\
\hline \multicolumn{6}{|c|}{ Reasons of migration (Ref = working or engaging in trade) } \\
\hline Following the migration of family members & 0.206 & $<0.001$ & 1.229 & 1.168 & 1.293 \\
\hline Marriage-related & 0.162 & $<0.001$ & 1.175 & 1.086 & 1.272 \\
\hline Else & 0.149 & $<0.001$ & 1.161 & 1.077 & 1.251 \\
\hline Settlement willingness (Ref = no) & 0.171 & $<0.001$ & 1.187 & 1.138 & 1.237 \\
\hline \multicolumn{6}{|l|}{ Self-rated health $(\operatorname{Ref}=$ good $)$} \\
\hline Neutral & -0.228 & $<0.001$ & 0.796 & 0.761 & 0.833 \\
\hline Poor & -0.080 & 0.305 & 0.923 & 0.793 & 1.075 \\
\hline Distance of medical facilities (Ref $=>15 \mathrm{~min}$ ) & 0.114 & $<0.001$ & 1.121 & 1.077 & 1.167 \\
\hline Health education $($ Ref $=$ no) & 0.980 & $<0.001$ & 2.664 & 2.548 & 2.784 \\
\hline Hearing about national BPHSs (Ref = no) & 2.382 & $<0.001$ & 10.824 & 10.359 & 11.311 \\
\hline Participation in social activities (Ref $=$ no) & 0.204 & $<0.001$ & 1.226 & 1.189 & 1.265 \\
\hline Participation in public affairs activities (Ref $=$ no) & 0.138 & $<0.001$ & 1.149 & 1.114 & 1.184 \\
\hline \multicolumn{6}{|c|}{ Type of people in touch (Ref = little contact with others) } \\
\hline People from the same hometown & -0.067 & 0.002 & 0.935 & 0.896 & 0.975 \\
\hline Natives in the inflow area & 0.069 & 0.001 & 1.072 & 1.028 & 1.118 \\
\hline Immigrants from places other than hometown & -0.031 & 0.270 & 0.970 & 0.918 & 1.024 \\
\hline
\end{tabular}

health administrations, communities, and young migrants need to make joint efforts of varying degrees to strengthen the equalization of BPHSs, and form external recourse supply and internal active participation to promote the establishment rate of health records. 


\section{Abbreviations}

NCDs: Non-communicable diseases; BPHS: Basic public health services; CMDS: China Migrants Dynamic Survey; STD: Sexually transmitted disease; AIDS: Acquired immune deficiency syndrome

\section{Acknowledgements}

We would like to acknowledge the National Health Commission Migrant Population Data Platform for providing data.

\section{Authors' contributions}

$\mathrm{XZ}$ and $\mathrm{HL}$ conceived and designed the study. $\mathrm{HS}, \mathrm{SZ}, \mathrm{SQ}, \mathrm{YL}$, and $\mathrm{YP}$ contributed to data acquisition and management. $X L, H S, Z R, H Z, M H, X F$, and $X G$ analyzed and interpreted the data. HS drafted the manuscript. $X Z$, $\mathrm{HL}, \mathrm{ZR}$, and $\mathrm{MH}$ commented on and edited the draft. All authors read and approved the final manuscript.

\section{Funding}

This study was supported by grant from Science and Technology Department of Jilin Province, China (Grant Number: 20200101133FG). The funder had no role in the study design, data collection, or preparation of the manuscript.

\section{Availability of data and materials}

The datasets used and/or analyzed during the current study are available from the corresponding author on reasonable request.

\section{Declarations}

\section{Ethics approval and consent to participate}

The 2017 China Migrants Dynamic Survey was approved by the China National Bureau of Statistics [No. NBS (2015)72], and written informed consent was obtained from all participants at the time of data collection. Use of the data for this study was approved by the Migrant Population Service Center, National Health Commission of China. As this study was a secondary analysis of de-identified data collected by the government, ethics approval has been exempted. All procedures performed in studies involving human participants were in accordance with the 1964 Helsinki Declaration and its later amendments or comparable ethical standards.

\section{Consent for publication}

Not applicable.

\section{Competing interests}

The authors declare that they have no competing interest.

\section{Author details}

'Department of Social Medicine and Health Management, School of Public Health, Jilin University, Changchun 130021, China. ${ }^{2}$ Department of Epidemiology and Biostatistics, School of Public Health, Jilin University, Changchun 130021, China.

\section{Received: 15 January 2021 Accepted: 12 March 2021}

\section{Published online: 24 March 2021}

\section{References}

1. Chen J, Chen S, Landry PF. Migration, environmental hazards, and health outcomes in China. Soc Sci Med. 2013;80:85-95. https://doi.org/10.1016/j. socscimed.2012.12.002.

2. NHFPC. Report on China's migrant population development in 2018. Beijing: China Population Press; 2018.

3. Liu XY. Exploring the features of youth migrants in Beijing. Think Tank Era. 2018;48:179-81.

4. Lu H, Kandilov IT, Zhu R. The impact of internal migration on the health of rural migrants: evidence from longitudinal data in China. J Dev Stud. 2020 56:840-55. https://doi.org/10.1080/00220388.2019.1590553.

5. Shao S, Wang M, Jin G, Zhao Y, Lu X, Du J. Analysis of health service utilization of migrants in Beijing using Anderson health service utilization model. BMC Health Serv Res. 2018;18:462. https://doi.org/10.1186/s12913-01 8-3271-y.

6. Rath B, Swenshon S, Haase K, Szeles T, Jung C, Jacobi F, et al. Using a mobile application to detect health needs among children and adolescents who are newly arrived migrants in Europe. J Public Health. 2019;41:840-9. https://doi.org/10.1093/pubmed/fdy191.

7. PRC opinions on promoting the basic public health services gradually equalization. 2009. http://www.gov.cn/jrzg/2009-07/10/content_1362010. htm. Accessed 10 July 2009.

8. Notice on implementing the national basic public health service projects in 2017. 2017. http://www.gov.cn/xinwen/2017-09/10/content_5223957.htm. Accessed 10 Sept 2017.

9. Qian Y, Ge D, Zhang L, Sun L, Li J, Zhou C. Does Hukou origin affect establishment of health records in migrant inflow communities? A nationwide empirical study in China. BMC Health Serv Res. 2018;18:704. https://doi. org/10.1186/s12913-018-3519-6.

10. Ran $\mathrm{R}$, Zhao $\mathrm{C}, \mathrm{Xu} X \mathrm{XG}$, Yao GQ. Improving perfect electronic health records and integrated health information in China: a case on disease management of diabetes. In: International conference on health information science; 2013. https://doi.org/10.1007/978-3-642-37899-7_20.

11. He H, Zhang J, Xiu D. China's migrant population and health. China Popul Dev Stud. 2019;3:53-66. https://doi.org/10.1007/s42379-019-00032-7.

12. Notice of the State Council on promoting equalization of basic services in the 13th five year plan. 2017. http://www.gov.cn/zhengce/content/2017-03/ 01/content 5172013.htm. Accessed 1 Mar 2017.

13. Qin JM. Progress in basic public health service projects in China. Chin J Public Health. 2017;33:1289-97. https://doi.org/10.11847/zgggws2017-33-09-01.

14. Jing Z, Wang Y, Ding L, Tang X, Feng Y, Zhou C. Effect of social integration on the establishment of health records among elderly migrants in China: a nationwide cross-sectional study. BMJ Open. 2019;9:e034255. https://doi. org/10.1136/bmjopen-2019-034255.

15. Deng B, Liang J. Status and related factors of public health services utilization among migrants with chronic diseases. Chin J Prev Control Chronic Non-Commun Dis. 2020;28:401-5. https://doi.org/10.16386/j.cjpccd. issn.1004-6194.2020.06.001.

16. Yan $\mathrm{Q}$, Tong L. Public health services utilization and related factors among young migrants. Chin J Public Health. 2019;35:680-4. https://doi.org/10.1184 7/zgggws1119401.

17. Yin Q, Xu QL. Establishment of health records and associated factors among migrants. Chin J Public Health. 2018;34:1351-5.

18. Li XF, Yang H, Wang H, Liu XJ. Effect of health education on healthcareseeking behavior of migrant workers in China. Int J Environ Res Public Health. 2020;17:2344. https://doi.org/10.3390/ijerph17072344.

19. Zhu JP. WHO: Youth under 44. Health Rev. 2013:22:13.

20. Guo XC, Huang L. Status and associated factors of establishment of health records among migrants - based on the China migrants dynamic survey of Sichuan province in 2014. Popul Dev. 2016;22:84-9. https://doi.org/10.3969/j. issn.1674-1668.2016.03.014.

21. Hu YN, Liang J. Status and related factors of public health services utilization among migrants in Hubei province. Occup Health. 2019:35:1381-5 https:// doi: CNKI:SUN:ZYJK.0.2019-10-022.

22. Hou JM, Zhao D. The determinants of self-rated health among migrants in China. Popul J. 2020;42:93-102. https://doi.org/10.16405/j.cnki.1004-129X.202 0.04.008.

23. Zheng $S Q$, Song ZD, Sun WZ. Do affordable housing programs facilitate migrants' social integration in Chinese cities? Cities. 2020;96:102449. https:// doi.org/10.1016/j.cities.2019.102449.

24. Lin SN, Wu FL, Li ZG. Social integration of migrants across Chinese neighbourhoods. Geoforum. 2020;112:118-28. https://doi.org/10.1016/j. geoforum.2020.04.008

25. Midi H, Sarkar S, Rana S. Collinearity diagnostics of binary logistic regression model. J Interdiscip Math. 2010;13:253-67. https://doi.org/10.1080/0972 0502.2010.10700699

26. Liu X, Wong H, Liu K. Outcome-based health equity across different social health insurance schemes for the elderly in China. BMC Health Serv Res. 2016;16:9. https://doi.org/10.1186/s12913-016-1261-5.

27. Qin XZ, Pan J, Liu GG. Does participating in health insurance benefit the migrant workers in China? An empirical investigation. China Econ Rev. 2014; 30:263-78. https://doi.org/10.1016/j.chieco.2014.07.009.

28. Li WH, Shen Y, Wang F, Zhu H, Liu SL, Na HY, et al. Public health services utilization and related factors among urban elderly: a multilevel model analysis. Chin J Public Health. 2019;35:71-5. https://doi.org/10.11847/ zgggws1117323.

29. Zhang JY, Lin SL, Liang D, Qian Y, Zhang DL, Hou ZY. Public health services utilization and its determinants among internal migrants in China: evidence 
from a nationally representative survey. Int J Environ Res Public Health. 2017;14:1002. https://doi.org/10.3390/ijerph14091002.

30. Souliotis K, Saridi M, Banou K, Golna C, Paraskevis D, Hatzakis A, et al. Health and health needs of migrants in detention in Greece: shedding light to an unknown reality. Glob Health. 2019;15:4. https://doi.org/10.1186/s12992-018-0448-4.

31. Liu JL, Mao Y. Rural resident experience on national basic public health services: a cross-sectional survey in 10 western provinces of China. Healthcare (Basel). 2019;7:160. https://doi.org/10.3390/healthcare7040160

32. Guo J, Wen HY, Zhou QY. Status and determinants of public health services utilization among migrants in China. Chin J Health Policy. 2014;7:51-6. https://doi.org/10.3969/j.issn.1674-2982.2014.08.01 1.

33. Wang $P G$, Chen $X G$, Gong J, Jacques-Tiura AJ. Reliability and validity of the personal social capital scale 16 and personal social capital scale 8: two short instruments for survey studies. Soc Indic Res. 2014;119:1133-48. https://doi. org/10.1007/s11205-013-0540-3.

34. Su L, Catherine H, Selene M. Comparison of health status and health care services utilization between migrants and natives of the same ethnic origin — the case of Hong Kong. Int J Environ Res Public Health. 2013;10: 606-22. https://doi.org/10.3390/ijerph10020606.

\section{Publisher's Note}

Springer Nature remains neutral with regard to jurisdictional claims in published maps and institutional affiliations.

Ready to submit your research? Choose BMC and benefit from:

- fast, convenient online submission

- thorough peer review by experienced researchers in your field

- rapid publication on acceptance

- support for research data, including large and complex data types

- gold Open Access which fosters wider collaboration and increased citations

- maximum visibility for your research: over $100 \mathrm{M}$ website views per year

At BMC, research is always in progress.

Learn more biomedcentral.com/submissions 